\title{
EXTRAÇÃO E CARACTERIZAÇÃO DE POLIHIDROXIALCANOATO- PHA DE BIOMASSA BACTERIANA CULTIVADA A PARTIR DE GLICERINA RESIDUAL EM ESCALA DE BIORREATOR
}

Gabriel Santos Vasconcelos'; Denilson de Jesus Assis'; Paulo Romano Cruz Correia $^{2}$; Janice Izabel Druzian ${ }^{1,2}$

${ }^{1}$ Escola Politécnica, Departamento de Engenharia Química, Universidade Federal da Bahia, R. Professor Aristides Novis n02,Federação; Salvador/BA; gabrielequfba@gmail.com

2 Programa de Pós-graduação em Ciência de Alimentos, Faculdade de Farmácia, Universidade Federal da Bahia, R. Barão de Jeremoabo s/n, Ondina; Salvador/BA

Resumo: O objetivo deste trabalho foi avaliar a eficiência de diferentes métodos de extração de PHAs obtidos a partir do substrato alternativo glicerina bruta residual do biodiesel. Os PHAs foram produzidos por Cupriavidus necator IPT 026 e glicerina em biorreator de $\mathrm{n} 4,5 \mathrm{~L}$ e extraídos da biomassa por método convencional (clorofórmio), por digestão alcalina, ácida, e via biológica (Tenébrio gigante). Apesar dos menores rendimentos, os PHAs obtidos com as extrações ácida e biológica apresentaram índices de cristalinidade menores, sugerindo ampla faixa de aplicação. As larvas consumiram as células e excretaram PHA nas fezes, e a separação com água resultou em PHA com propriedades mais apropriadas e menor degradação. O método de extração tem grande influência no rendimento e nas propriedades do bioplástico.

Palavras-Chave: Cupriavidus necator; Polihidroxialcanoatos; Bioplástico.

\section{EXTRACTION AND POLYHYDROXIALCANOATE-PHA FROM BACTERIAL BIOMASS CULTIVATED WITH RESIDUAL GLYCERIN IN BIORREATOR SCALE}

\begin{abstract}
The objective of this work was to evaluate the efficiency of the different PHA extraction methods obtained from the alternative substrate composed of biodiesel residual glycerin. PHA was produced by Cupriavidus necator IPT 026 and glycerin in a $4.5 \mathrm{~L}$ bioreactor and extracted from the cell biomass with chloroform (conventional), alkaline and acid digestion methods, and biological route (Giant Tenebrio). Despite the lower yields, the PHAs obtained with the acid and biological extractions presented lower crystallinity indexes, suggesting a wide application range. Larvae consumed cells and excreted PHA in feces, and separation with water resulted in PHA with more appropriate properties and less degradation. The extraction method has great influence on the yield and properties of the bioplastic.
\end{abstract}

Keywords: Cupriavidus necator, Polyhydroxyalkanoates; Bioplastic 


\section{INTRODUÇÃO}

Os polihidroxialcanoatos (PHAs) são poliésteres de origem microbiana acumulados intracelularmente sob a forma de corpos de inclusão por diversos gêneros bacterianos. Geralmente, a síntese destes biopolímeros ocorre em meio com ampla disponibilidade de fonte de carbono (glicose ou sacarose) e limitação de fonte de micronutrientes, como nitrogênio, fósforo, enxofre ou magnésio [1]. Os PHAs podem ter massa molecular de $10^{3}$ a $10^{5}$ Da e ser classificados em três grupos de acordo com o número de unidades de carbono do(s) monômero(s): PHA de comprimento curto com 3-5 unidades de carbono (scl-PHA), PHA de cadeia média com 6-14 unidades de carbono (mcl-PHA), e de cadeia longa com 15 ou mais unidades de carbono (Icl-PHA) [1, 2].

Os PHAs vêm recebendo grande visibilidade, principalmente devido às propriedades, como biodegrabilidade, baixa toxicidade, biocompatibilidade, termoplasticidade e propriedades mecânicas adequadas, o que faz com que esses podendo ser empregados na fabricação de películas, garrafas e embalagens biodegradáveis. Ainda que os PHAs apresentem propriedades equivalentes à maioria dos plásticos petroquímicos, sua produção apresenta altos custos, onde cerca de $40 \%$ deles estão relacionados com a matéria-prima que compõem o meio de cultivo. Desse modo, a utilização de fontes de carbono alternativas, constitui uma das formas mais importantes de baratear seus custos de produção [1-5].

Os microrganismos podem consumir grande parte dos resíduos industriais que contem carbono. A glicerina é um importante subproduto da obtenção de biodiesel, correspondendo a $10 \%$ do volume de produto da reação de transesterificação. A utilização da glicerina residual do biodiesel (GRB) em bioprocessos torna-se uma alternativa promissora, contribuindo para redução de custos de processo e de possíveis impactos ambientais [1]. Além da fonte de carbono utilizada no meio de cultivo, estima-se que o impacto do custo de recuperação de PHA pode atingir até $50 \%$ do valor do produto, a depender das variáveis do processo de separação empregado e do teor de PHAs acumulado. Consequentemente, diversas estratégias podem ser empregadas para extrair o polímero, sendo mais utilizados os métodos químicos, mecânicos ou combinação destes [2,3].

As células bacterianas apresentam uma estrutura protetora relativamente simples, uma parede celular de peptídeoglicano e uma membrana plasmática lipoproteica, de modo que a extração dos PHAs destas por meio de solventes consiste numa técnica amplamente utilizada devido a facilidade na operação e sua simplicidade. Essa é dividida em três etapas: um pré-tratamento para romper as células de modo que os grânulos de PHA se tornem acessíveis, em seguida esses grânulos tornam-se solúveis em um solvente adequado, finalizando com a precipitação em um não solvente como metanol ou etanol sob forma gelada [1,3-7].

A extração utilizando solventes é a mais utilizada, principalmente quando há necessidade de alta pureza, pois evita a degradação do polímero além de promover a remoção das endotoxinas das células. Entretanto, para este método, são mais 
utilizados, solventes clorados como clorofórmio, 1,2-dicloetano. Alternativamente, podem ser usados solventes não-clorados, como acetona (preferida para mclPHAs), e carbonato de 1,2-propileno. O emprego de solventes tóxicos e altamente voláteis, como o clorofórmio é contraditório à ideia de produzir PHA para minimizar as agressões ambientais causadas pelos polímeros de origem petroquímica. Além disso, a utilização destes solventes halogenados exige um rigoroso controle, devido à segurança do processo e problemas ambientais [3,4].

O método da digestão envolve mecanismos de digestão química, enzimática e biológica para liberação de PHAs das células. No método químico, a extração de PHAs envolve a solubilização e digestão de materiais não poliméricos celulares, como ácidos nucleicos, lipídios, fosfolipídios, peptídeoglicano e materiais proteicos. Os digestores mais utilizados são o hipoclorito de sódio, hidróxido de sódio e o ácido sulfúrico $\left(\mathrm{H}_{2} \mathrm{SO}_{4}\right)$. A eficácia da recuperação depende da espécie microbiana da qual será realizada a extração [3,4].

Outro processo consiste na utilização de larvas de insetos na digestão da biomassa contendo PHA. As larvas excretam os grânulos de PHA menos degradados na forma de fezes esbranquiçadas [2]. Neste contexto, o objetivo do trabalho foi avaliar a eficiência de diferentes métodos de extração de PHA obtido a partir do substrato alternativo glicerina bruta residual GRB do biodiesel, contribuindo para a redução dos custos e garantia da qualidade do polímero.

\section{METODOLOGIA}

\subsection{Reativação e Manutenção dos Microrganismos Produtores de PHA}

As cepas Cupriavidus necator IPT 026 foram reativadas em caldo nutriente composto de 5,0 $\mathrm{g} \mathrm{L}^{-1}$ de peptona de carne, 3,0 $\mathrm{g} \mathrm{L}^{-1}$ de extrato de carne e incubadas em estufa bacteriológica $\left(30^{\circ} \mathrm{C}, 1 \mathrm{~h}\right)$. Em seguida, foram transferidos 100 $\mu \mathrm{L}$ da suspensão para placas de Petri contendo caldo nutriente acrescido de ágar $(1,5 \%, \mathrm{~m} / \mathrm{v})$ e incubadas a $30^{\circ} \mathrm{C}$ por $24 \mathrm{~h}$.

\subsection{Produção de PHAs}

Os biopolímeros foram produzidos a partir de duas pré-culturas e uma cultura final. Na primeira pré-cultura foram transferidos $10 \mu \mathrm{L}$ de colônia dos microrganismos para $50 \mathrm{~mL}$ de meio nutriente, constituído por $3,0 \mathrm{~g} \mathrm{~L}^{-1}(\mathrm{~m} / \mathrm{v})$ de extrato de carne e $5,0 \mathrm{~g} \mathrm{~L}^{-1}(\mathrm{~m} / \mathrm{v})$ de peptona e incubado em agitador orbital (Tecnal, Mod. TE-424) a $150 \mathrm{rpm}$ e $35^{\circ} \mathrm{C}$ por $24 \mathrm{~h}$. Na segunda pré-cultura foram transferidos $10 \%(\mathrm{~m} / \mathrm{v})$ da primeira pré-cultura para o meio mineral composto de ácido nitriloácetico $\left(1,9 \mathrm{~g} \mathrm{~L}^{-1}, \mathrm{~m} / \mathrm{v}\right)$, citrato ferroso de amônia $\left(1,0 \mathrm{~g} \mathrm{~L}^{-1}, \mathrm{~m} / \mathrm{v}\right)$, $\mathrm{MgSO}_{4} .7 \mathrm{H}_{2} \mathrm{O}\left(0,5 \mathrm{~g} \mathrm{~L}^{-1}, \mathrm{~m} / \mathrm{v}\right), \mathrm{CaCl}_{2} .2 \mathrm{H}_{2} \mathrm{O}\left(0,5 \mathrm{~g} \mathrm{~L}^{-1}, \mathrm{~m} / \mathrm{v}\right),\left(\mathrm{NH}_{4}\right)_{2} \mathrm{SO}_{4}\left(3,4 \mathrm{~g} \mathrm{~L}^{-1}, \mathrm{~m} / \mathrm{v}\right)$, GRB $\left(2,0 \mathrm{~g} \mathrm{~L}^{-1}, \mathrm{~m} / \mathrm{v}\right)$ e incubado em agitador orbital a $35^{\circ} \mathrm{C}, 150 \mathrm{rpm}$ por $24 \mathrm{~h}$. 
Foram transferidos $10 \%(\mathrm{v} / \mathrm{v})$ desta cultura para um meio limitante, composto por ácido nitriloácetico $\left(1,9 \mathrm{~g} \mathrm{~L}^{-1}, \mathrm{~m} / \mathrm{v}\right)$, citrato ferroso de amônia $\left(1,0 \mathrm{~g} \mathrm{~L}^{-1}, \mathrm{~m} / \mathrm{v}\right)$, $\mathrm{MgSO}_{4} .7 \mathrm{H}_{2} \mathrm{O}\left(0,5 \mathrm{~g} \mathrm{~L}^{-1}, \mathrm{~m} / \mathrm{v}\right), \mathrm{CaCl}_{2} .2 \mathrm{H}_{2} \mathrm{O}\left(0,5 \mathrm{~g} \mathrm{~L}^{-1}, \mathrm{~m} / \mathrm{v}\right), \mathrm{Na}_{2} \mathrm{HPO}_{4} .12 \mathrm{H}_{2} \mathrm{O}\left(0,2 \mathrm{~g} \mathrm{~L}^{-}\right.$ $\left.{ }^{1}, \mathrm{~m} / \mathrm{v}\right), \mathrm{KH}_{2} \mathrm{PO}_{4}\left(3,7 \mathrm{~g} \mathrm{~L}^{-1}, \mathrm{~m} / \mathrm{v}\right)$ e GRB $\left(20,0 \mathrm{~g} \mathrm{~L}^{-1}, \mathrm{~m} / \mathrm{v}\right)$ em $\mathrm{pH}$ ajustado para 7.0 . A cultura final foi conduzida em biorreator $\left(35^{\circ} \mathrm{C}, 500 \mathrm{rpm}, 1 \mathrm{vvm}\right.$ de aeração por $72 \mathrm{~h}$ ) [1].

\subsection{Métodos de Extração de PHAs}

Após o cultivo em biorreator, as células de IPT 026 foram separadas por ultracentrifugação a $5{ }^{\circ} \mathrm{C}, 42200 \times \mathrm{g}$ por 20 minutos (HITACHI, model CR 22G). O sobrenadante foi descartado. Para a extração dos PHAs da biomassa celular foram testados 4 métodos. Os PHAs foram extraídos convencionalmente da biomassa celular seca por ação de clorofórmio a $60{ }^{\circ} \mathrm{C}$ por $2 \mathrm{~h}$. Alternativamente, foram testadas duas digestões químicas: utilizando hipoclorito de sódio a $13 \%(\mathrm{v} / \mathrm{v}), \mathrm{pH}$ 12,3 por $1 \mathrm{~h}$, seguida de precipitação do polímero com adição de água; e utilizando ácido sulfúrico $\left(0,1 \mathrm{~mol}^{-1}\right)$ a $100^{\circ} \mathrm{C}$ por $2 \mathrm{~h}$, seguido de neutralização e centrifugação. A digestão biológica também foi testada, onde larvas de Tenébrio gigante (Zophobas morio) foram alimentados com a biomassa celular de IPT 26 e os sedimentos fecais foram recolhidos e sujeitos a purificação adicional utilizando solução aquosa de SDS $1 \%(\mathrm{~m} / \mathrm{v})\left(\mathrm{com}\right.$ e sem aquecimento à $\left.50^{\circ} \mathrm{C}\right)$. Os $\mathrm{PHAs}$ obtidos pelos diferentes métodos foram secos em estufa $\left(35^{\circ} \mathrm{C}\right)$ e as concentrações expressas em g L ${ }^{-1}[1,2,5,6]$.

\subsection{Massa Molecular dos PHAs}

As massas moleculares do PHA foram obtidos por sistema cromatográfico GPC-CLAE (Perkin Elmer 200) com detector de índice de refração (IR) (Perkin Elmer) e uma coluna Shodex $807 \mathrm{KD}$. Os PHAs foram dissolvidos em clorofórmio a $0,7 \mathrm{mg} \mathrm{mL}^{-1}$ e filtrados em membrana de PTFE de 0,22 $\mu \mathrm{m}$. A fase móvel foi clorofórmio (1 $\left.\mathrm{mL} \mathrm{min}^{-1}\right)$. A massa molecular média ponderada ( $\mathrm{Mw}$ ) e o número médio de massa molecular (Mn) foram calculadas com uma curva constituída com padrões de poliestireno (682 a 1.670.000 Da, Polymer Standards Service, EUA), e o índice de polidispersão (Đ) por meio da relação (Mw/Mn), [1].

\section{5. Índice de Cristalinidade e FTIR dos PHAs}

Os índices de cristalinidade $(\mathrm{Xc})$ foram calculados por meio do método de Difração de Raios X (DRX). Os difratogramas das amostras foram obtidos em um equipamento (SHIMADZU modelo XRD 6000) operando com fonte de radiação Cuג, $40 \mathrm{kV}$ e $30 \mathrm{~mA}$.

O PHA extraído foi examinado por FTIR-ATR para estudo do polímero obtido. 


\section{RESULTADOS E DISCUSSÃO}

A Tabela 1 apresenta os resultados de recuperação, massas moleculares (Mw) e percentual de cristalinidade dos PHAs extraídos da biomassa de C. necator IPT 026 cultivadas em meio contendo GRB e extraídos com clorofórmio e digestão química com hipoclorito de sódio e ácido sulfúrico. $\mathrm{O}$ método de extração utilizando clorofórmio foi o que mais favoreceu a extração de PHA, resultando em $28 \%$ do polimero (Tabela 1). Esses resultados condizem com o fato desse solvente ser amplamente utilizado em escala comercial, devido sua alta eficiência de extração. Esta eficiência fundamenta-se, principalmente na capacidade que o solvente quente tem de modificar a permeabilidade da membrana celular bacteriano e dissolução do polímero no interior das células, formando uma suspensão dos fragmentos de células na solução de polímeros e solvente. Entretanto, o seu emprego é contraditório à ideia de que estes polímeros vêm sendo amplamente estudados para minimizar as agressões ambientais causadas pelos polímeros de origem petroquímica. Além disso, o uso do clorofórmio resultou PHA com massa molecular em torno de $22 \%$ acima dos valores obtidos com as demais extrações. No entanto, a energia térmica imposta pelo clorofórmio aquecido pode ser superior à energia das ligações covalentes do PHA e causar rompimentos das ligações e, consequentemente provocar a redução da massa molecular do polímero original. Assim, o uso desse solvente promoveu um maior alinhamento das cadeias mais curta de PHAs, gerando elevado percentual de regiões cristalinas, tornando-o mais rígido e menos apto para o processamento por extrusão [3,7,8,4].

Tabela 1. Biomassa seca, produção de PHA, massas moleculares médias ponderadas $(\mathrm{Mw})$, número médio de massa molecular $(\mathrm{Mn})$, índice de polidispersão $(\bigoplus)$ e índice de cristalinidade $(\mathrm{XC})$ dos PHAs produzidos por cultivo submerso em meio de cultivo contendo glicerina bruta residual do biodiesel (GRB) e extraídos por métodos diferentes.

\begin{tabular}{|c|c|c|c|c|c|c|c|}
\hline $\begin{array}{l}\text { Método de } \\
\text { extração }\end{array}$ & $\begin{array}{c}\text { Biomassa } \\
\text { (g) }\end{array}$ & $\begin{array}{l}\text { PHA } \\
\text { (g) }\end{array}$ & $\begin{array}{c}\text { PHA (g/g de } \\
\text { biomassa) }\end{array}$ & $\begin{array}{c}M w \\
\left(\times 10^{5} \mathrm{Da}\right)\end{array}$ & $\begin{array}{c}\text { Mn } \\
\left(\times 10^{5} \mathrm{Da}\right)\end{array}$ & $\boldsymbol{\theta}$ & $\begin{array}{l}X_{c} \\
(\%)\end{array}$ \\
\hline Clorofórmio & 3,0 & 0,84 & 2,52 & 7,62 & 7,93 & 1,04 & 48,88 \\
\hline $\begin{array}{l}\text { Hipoclorito } \\
\text { de sódio }\end{array}$ & 3,0 & 0,74 & 2,22 & 5,95 & 6,30 & 1,06 & 65,67 \\
\hline $\begin{array}{l}\text { Ácido } \\
\text { sulfúrico }\end{array}$ & 3,0 & 0,51 & 1,53 & 6,05 & 6,17 & 1,02 & 39,88 \\
\hline
\end{tabular}

A hidrólise alcalina com hipoclorito promoveu a liberação de PHA no meio, resultando em extração de $25 \%$ do polímero, portanto, menor comparado com a extração convencional (clorofórmio), Tabela 1. O hipoclorito de sódio é um agente oxidante não seletivo que pode digerir tanto o material não polimérico como os grânulos poliméricos, o que resultou na redução da massa molecular do biopolímero, 
comparado ao método com clorofórmio. Assim, a utilização desse agente resultou em PHAs com menores valores de massa molecular e, consequentemente, maiores percentuais de regiões cristalinas (65,67\%). O hipoclorito de sódio pode reduzir Mw em até $50 \%[3,6]$. De acordo com Serafim et al. (2008), este percentual condiz com biopolímeros rígidos e inadequados para o processo de extrusão [9].

Por outro lado, a hidrólise com ácido sulfúrico resultou na redução da extração de PHA (17\%) em relação à extração com clorofórmio e hidrólise alcalina, com Mw próximo ao do PHA obtido com a extração com hipoclorito, (Tabela 1). 0 fato pode estar associado à degradação das células e com hidrólise do polímero. Entretanto, o método favoreceu a recuperação de polímeros com menor percentual de regiões cristalina $(39,88 \%)$, sendo considerado um biopolímero flexível e elástico e, portanto, o mais adequado para aplicação como matriz polimérica na produção de embalagens por método de extrusão [9]. Constata-se também que todos os PHAs produzidos apresentaram índice de polidispersão $(\boxminus)>1$, indicando uma distribuição mais uniforme dos tamanhos moleculares [1].

As larvas de Tenébrio gigante (Zophobas morio) foram alimentadas com a biomassa liofilizada de IPT 026 produzida com glicerina residual do biodiesel. As larvas excretaram PHA nas fezes esbranquiçadas (Figura 1). A purificação das fezes esbranquiçadas com água e detergente resultou em $13 \%$ de $\mathrm{PHA}$ em relação a biomassa celular, portanto menor do que a extração com os outros três métodos, entretanto os resultados de caracterização em andamento indicam que o polímero apresenta propriedades diferentes dos extraídos pelos outros métodos (Figura 2).

Figura 1. llustração do Tenébrio gigante, do consumo de biomassa de IPT 026 pelas larvas (material mais claro indicado), e a consequente eliminação de fezes esbranquiçadas (parte esfarelada coletada no tubo Eppendorf) contendo PHA.

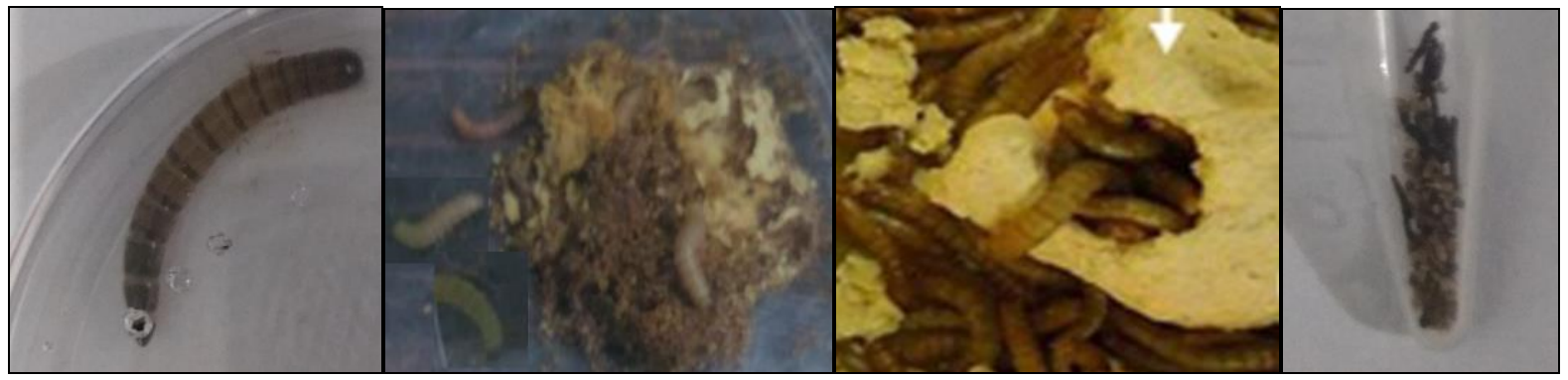

Figura 2. FTIR: A) PHA da biomassa celular extraida com cloroformio; B) Fezes eliminadas na forma de pelletes escuros pelos tenebrios alimentados com biomassa celular, e C) PHA extraido das fezes. 

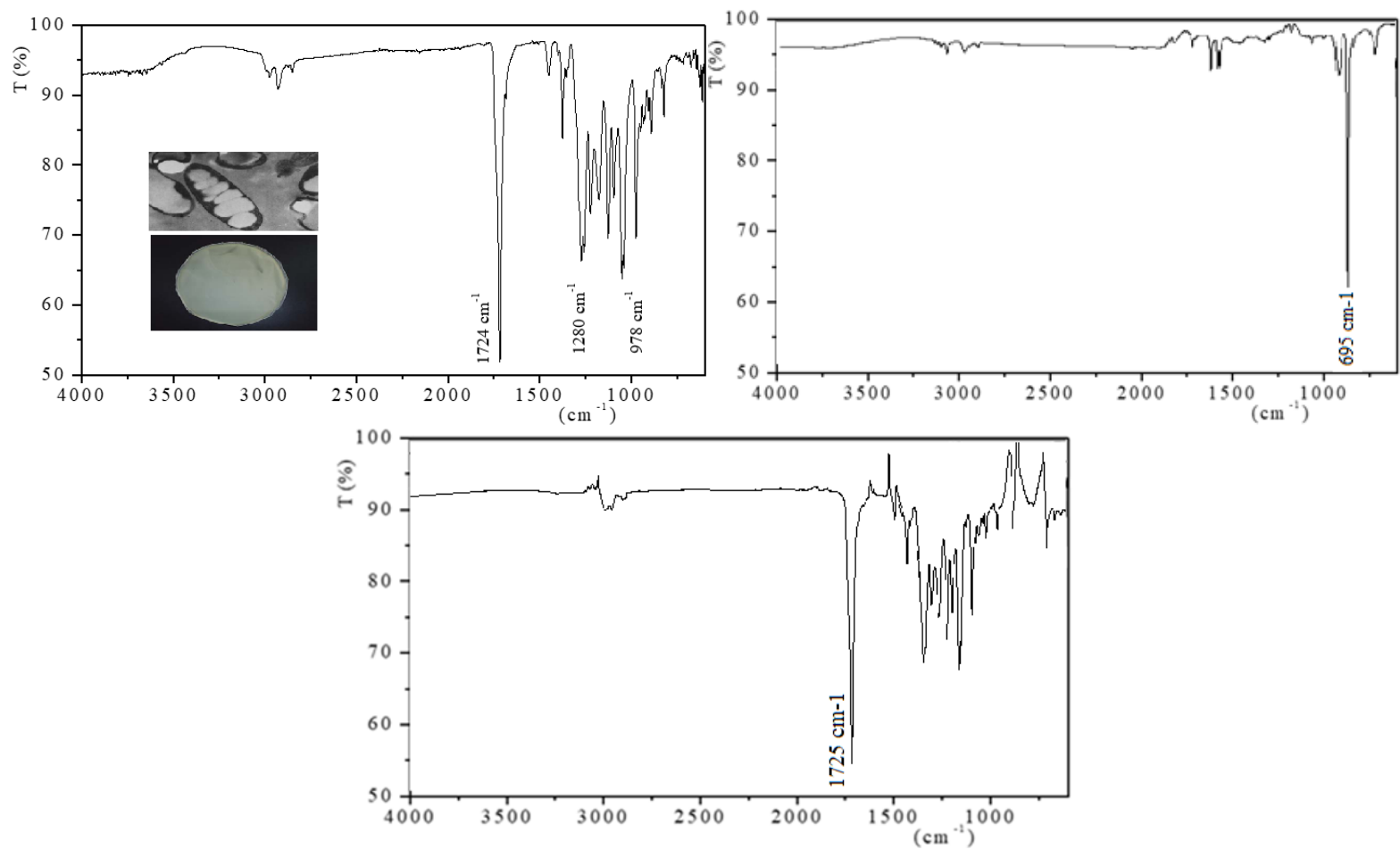

Constata-se uma similaridade entre as bandas do FTIR do PHA extraído diretamente da biomassa celular do IPT 026 com clorofórmio (Figura 2A) com as bandas do PHA extraído das fezes do inseto (Figura 2C). O FTIR das fezes não apresenta as bandas de $\mathrm{C}=0 \mathrm{em} 1720 \mathrm{~cm}-1$ que caracteriza ésteres (Figura 2B).

As larvas podem recuperar os grânulos de PHA da célula do microrganismos de IPT 026, enquanto os outros componentes celulares são digeridos. A utilização de larvas de Tenébrio gigante na etapa de extração, além de resultar em PHA com propriedades diferenciadas, apresenta as vantagens adicionais de não ser tóxico ao ser humano e ao ambiente, e produzir concomitantemente os insetos que podem ser destinados a inúmeras aplicações, sendo portanto inovador no estado da técnica. As larvas apresentam alta densidade de crescimento, exigindo menos água e espaço, consumindo em torno de $10 \%$ de seu peso por dia de biomassa celular.

Os insetos podem ser destinados a alimentação de peixes e pássaros, ou como iscas de pesca. A biomassa de insetos pode ser processada na forma de farinha e apresenta alto teor proteico e elevada composição nutricional, que podem ser destinadas a ração animal e alimentação humana [2,10].

A produção concomitante de PHA e insetos, juntamente com o emprego do substrato alternativo de baixo custo usado no cultivo de PHA (glicerina bruta do biodiesel), podem contribuir para a redução dos custos de obtenção do PHA, e aumentar a competitividade comercial do bioplástico, contribuindo para a proteção do meio ambiente.

\section{CONCLUSÃO}


A extração com clorofórmio apresentou maior rendimento e PHA com massa molecular superior, quando comparada aos outros métodos. Por outro lado os valores de índice de cristalinidade foram menores nos PHAs obtidos com a extração ácida e biológica, indicando maior teor do polímero amorfo, o que facilita a sua processabilidade por fusão no processo de moldagem por extrusão, sugerindo ampla faixa de aplicação, principalmente como embalagens biodegradáveis. Todos os métodos de extração resultaram em PHAs com distribuição uniforme dos tamanhos moleculares. Apesar do menor rendimento, a utilização de larvas para a extração de PHA é inovador e resulta em polímero com propriedades diferenciadas, apresentando as vantagens adicionais de não ser tóxico e produzir concomitantemente os insetos que podem ser destinados a inúmeras aplicações. Esta extração biológica, juntamente com o emprego do substrato alternativo de baixo custo como glicerina bruta residual para a biossíntese de PHA, pode reduzir os seus custos de produção e aumentar a competitividade comercial do bioplástico e proteção do meio ambiente.

\section{Agradecimentos}

Ao CNPQ pelo apoio financeiro (421118/2016-4) e bolsa PIBIT do primeiro autor.

\section{REFERÊNCIAS}

${ }^{1}$ ASSIS, D. J.; GOMES, G. V. P.; PASCOAL, D. R. C.; PINHO, L. S.; CHAVES, L. B. O.; DRUZIAN, J. I. Simultaneous biosynthesis of polyhydroxyalkanoates and extracellular polymeric substance (EPS) from crude glycerol from biodiesel production by different bacterial strains. Applied Biochemistry and Biotechnology, v. 180, n. 6, p. 1110-1127, 2016.

2 MURUGAN, P.; HAN, L.; GAN, C.; MAURER, F. H. J.; SUDESH, K. A new biological recovery approach for PHA using mealworm, Tenebrio molitor. Journal of $\begin{array}{lllll}\text { Biotechnology, } & \text { v. } & 239, & \text { p. } & 98-105,\end{array}$ http://dx.doi.org/10.1016/j.jbiotec.2016.10.012.

3 JACQUEL, N.; LO, C. W.; WEI, Y. H.; WU, H. S. Isolation and purification of bacterial poly (3-hydroxyalkanoates). Biochemical Engineering Journal, v. 39, n. 1, p. 15-27, 2008.

${ }^{4}$ QUINES, L. K. M.; SCHMIDT, M.; ZANFONATO, K.; SCHMIDELL, W.; ARAGÃO, G. M. F. Método de extração de polihidroxialcanoatos a partir de biomassa bacteriana. Química Nova, v. 38, p. 1207-1218, 2015. 
5 HEINRICH, D.; MADKOUR, M. H.; Al-GHAMDI, M. A.; SHABBAJ, I. I.; STEIBÜCHEL, A. Large scale extraction of poly(3-hydroxybutyrate) from Ralstonia eutropha H16 using sodium hypoclorite. AMB Express, v. 2, p. 1-6, 2012.

6 YU, J.; STAHL, H. Microbial utilization and biopolyester synthesis of bagasse hydrolysates. Bioresource Technology, v. 99, p. 8042-8048, 2008.

7 LÓPEZ-ABELAIRAS, M.; GARCÍA-TORREIRO, M.; LÚ-CHAU, T.; LEMA, J. M.; STEINBÜCHEL, A. Comparison of several methods for the separation of poly(3hydroxybutyrate) from Cupriavidus necator $\mathrm{H} 16$ cultures. Biochemical Engineering Journal, v. 93, p. 250-259, 2015.

8 TORRES, A. A. U.; ALMEIDA, J. R. M.; HABAS, J. Avaliação do efeito de um óleo parafínico sobre o comportamento físico-químico de tubulações de polietileno de alta densidade. Polímeros, v. 20, p. 331-338, 2011.

${ }^{9}$ SERAFIM, L. S.; LEMOS, P. C.; ALBUQUERQUE, M. G.; REIS, M. A. Strategies for PHA production by mixed cultures and renewable waste materials. Applied and Environmental Microbiology, v. 81, p. 615-628, 2008.

${ }^{10}$ CARVALHO, N. M.; TEIXEIRA, F.; SILVA, S.; MADUREIRA, A. R.; PINTADO, M. E. Potential prebiotic activity of Tenebrio molitor insect flour using an optimized in vitro gut microbiota model. Food \& Function, v. 10, n. 7, 2019. DOI: $10.1039 / \mathrm{C} 8 \mathrm{FO} 01536 \mathrm{H}$ 